\title{
Effect of 5-Methylbenzotriazole on the Corrosion Inhibition of Brass in NaCl Solution
}

\author{
T. GOWRANI
}

Department of Chemistry, NGM College, Pollachi- 642 001, Tamilnadu, India gowranivijay@gmail.com

Received 20 March 2014 / Accepted 21 April 2014

\begin{abstract}
The corrosion behavior of brass in the presence of inhibitor namely 5-methyl benzotriazole (MBTA) has been investigated in $3 \% \mathrm{NaCl}$ medium. The inhibition efficiency of MBTA was evaluated from chemical and electrochemical techniques. Experimental studies showed that MBTA reduces markedly the corrosion of brass in $3 \% \mathrm{NaCl}$ solution and this reduction in corrosion rates enhances with increasing concentration of MBTA. Weight loss study revealed that the formulation consisting of $150 \mathrm{ppm}$ of MBTA showed $71 \%$ inhibition efficiency. Polarization studies also revealed that the inhibitor act as mixed type for brass in chloride solution. The characterization of corrosion product on brass in presence of MBTA was analysed by FTIR.
\end{abstract}

Keywords: Brass, 5-Methylbenzotriazole, Impedance spectroscopy, Polarization studies, FTIR.

\section{Introduction}

Copper has a wide range of applications due to its good properties ${ }^{1-3}$. Brass has been widely used as tubing material for condensers and heat exchangers in various cooling water system ${ }^{4-9}$. Due to the electrodissolution of metal in chloride solutions, there is a growing interest in inhibitors, for the application of copper or its alloys in marine environments. $N$-heterocyclic compounds have been widely used as corrosion inhibitors. Among these azoles are known as one of the best corrosion inhibitors for copper and its alloys in a wide range of environments ${ }^{10-13}$. Benzotriazole is a good anodic inhibitor for copper in acidic conditions ${ }^{14}$ and in chloride solutions ${ }^{15}$. Frignani et al. ${ }^{16}$ investigated the influence of alkyl chain on the protective effects of benzotriazole towards copper in acidic chloride solution and concluded that the inhibitors effectively control corrosion.

Although there is an extensive literature on the corrosion properties of triazole such as aminotriazole and benzotriazole on steel and copper ${ }^{17-19}$, there are very few reports devoted to the various functional groups in BTA derivatives on the corrosion of brass. In the cases where these benzotriazole derivatives have been considered, they have first been introduced as effective corrosion inhibitors in cooling water systems. 
The present work is devoted to the investigation of the corrosion behavior of brass in $\mathrm{NaCl}$ medium. Further, the study was extended to understand the effect of MBTA in the corrosion inhibition of brass. The effect of the addition of MBTA as inhibitor on the corrosion behavior of brass has been studied by the weight loss method and some electrochemical methods. The passive film characterization was carried by FTIR spectra.

\section{Experimental}

The chemical composition (weight percent) of the of the brass plate used in these tests was $65 \% \mathrm{Cu}, 35 \% \mathrm{Zn}, 0.1385 \% \mathrm{Fe}, 0.0635 \% \mathrm{Sn}$ and the rest $\mathrm{Pb}, \mathrm{Mn}, \mathrm{Ni}, \mathrm{Cr}, \mathrm{As}, \mathrm{Co}, \mathrm{Al}$ and $\mathrm{Sr}$ as analyzed by optical emission spectrophotometer. The brass specimens were polished mechanically with SiC papers (120 -1200 grit), washed with double distilled water and degreased in acetone $\mathrm{e}^{20}$. The solutions were prepared from AR chemicals using DD water. The structure of MBTA is given in Figure 1.<smiles>Cc1ccc2[nH]nnc2c1</smiles>

Figure 1. Structure of 5-methylbenzotriazole

\section{Weight loss method}

Weight loss measurements were carried out using brass specimen of size $4 \times 1 \times 0.4 \mathrm{~cm}$. The specimens were immersed in $100 \mathrm{~mL}$ of $3 \% \mathrm{NaCl}$ solution with and without inhibitors at room temperature for $24 \mathrm{~h}$.

\section{Potentiodynamic polarization study}

The potentiodynamic polarization studies were carried out with brass strips having an exposed area of $1 \mathrm{~cm}^{2}$. The cell assembly consisted of brass as working electrode, a platinum foil as counter electrode and a saturated calomel electrode (SCE) as a reference electrode with a Luggin capillary bridge. Polarization studies were carried out using a potentiostat/galvanostat and the data obtained were analyzed.

The working electrode was immersed in a $3 \% \mathrm{NaCl}$ solution and allowed to stabilize for half an hour $^{21}$. Each electrode was immersed in a $3 \% \mathrm{NaCl}$ solution in the presence and absence of optimum concentrations of the inhibitors to which a current of $1.5 \mathrm{~mA} \mathrm{~cm}^{-2}$ was applied for $15 \mathrm{~min}$ to reduce oxides. The cathodic and anodic polarization curves for brass specimen in the test solution with and without inhibitor were recorded at a sweep rate of 1 $\mathrm{mV} \mathrm{s}^{-1}$. The inhibition efficiencies of the compounds were determined from corrosion currents using the Tafel extrapolation method.

\section{Electrochemical AC impedance studies}

$\mathrm{AC}$ impedance measurements were conducted at room temperature in the frequency range $\mathrm{e}^{22}$ of $100 \mathrm{kHz}$ to $1 \mathrm{mHz}$ and the results were analysed.

\section{FTIR spectra}

The film that developed on the surface of brass during polarization measurements in the presence of the inhibitor was washed with water, dried and collected by scrapping from the surface of the alloy for subsequent spectral analysis and FTIR spectra were recorded ${ }^{23}$. 


\section{Results and Discussion}

\section{Weight loss method}

Table 1 shows the inhibition efficiency (IE) and corrosion rate (CR) of brass by weight loss measurements at different inhibitor concentrations in $3 \% \mathrm{NaCl}$ at room temperature. The $\mathrm{CR}$ and IE were calculated using the following equation.

$$
\mathrm{C}=(534 \times \mathrm{W}) /(\mathrm{D} \times \mathrm{T} \times \mathrm{A})
$$

Table 1. Inhibition efficiency of MBTA on brass in 3\% $\mathrm{NaCl}$ by weight loss method

\begin{tabular}{ccc}
\hline Inhibitor concentrarion, ppm & Corrosion rate, mils year $^{-1}$ & Inhibition Efficiency, \% \\
\hline Blank & 0.395 & \\
MBTA 10 & 0.282 & 28.61 \\
50 & 0.225 & 43.04 \\
100 & 0.169 & 57.20 \\
150 & 0.113 & 71.39 \\
200 & 0.169 & 57.20 \\
250 & 0.282 & 28.61 \\
300 & 0.338 & 14.43 \\
\hline
\end{tabular}

Where $\mathrm{A}$ is the area, $\mathrm{T}$ the immersion time, $\mathrm{W}$ the weight loss and $\mathrm{D}$ the density of the specimen. It has been observed that the IE increases and CR decreases with increase in concentration of inhibitors and the optimum efficiency was $71 \%$ at $150 \mathrm{ppm}$ concentration. The percentage of IE for different concentration of MBTA (ppm) increases in the following order $10<50<100<150$ and decreases at $200 \mathrm{ppm}$.

\section{Potentiodynamic polarization studies}

The cathodic and anodic polarization curves of brass in $3 \% \mathrm{NaCl}$ solution and with optimum concentrations of MBTA are shown in Figure 2. It is evident that in the presence of inhibitor, the cathodic and anodic curves were shifted to more positive potential region and the shift was found dependent on concentration of the inhibitor. The CR and IE ${ }^{24}$ were calculated from the following equations and the values were presented in the Table 2.

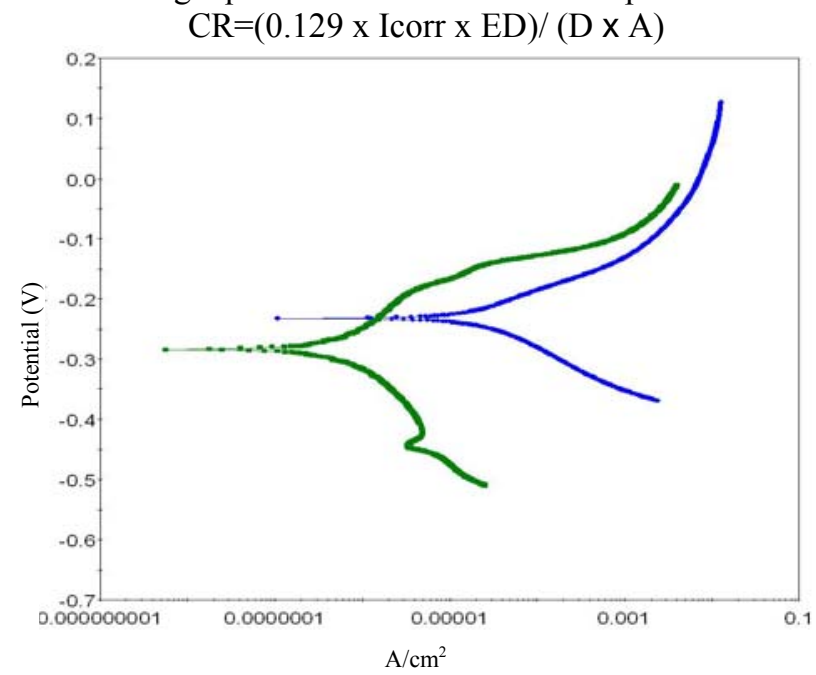

Figure 2. Polarisation curves for brass in $3 \% \mathrm{NaCl}(\mathrm{O} \rightarrow$ blank, $\square \rightarrow 150$ pppm MBTA $)$ 
Where EW is the equivalent weight $(\mathrm{g})$, D the density $\left(\mathrm{g} \mathrm{cm}^{-3}\right)$, A the area $\left(\mathrm{cm}^{2}\right)$ of the specimen and Icorr(inh) and Icorr are the corrosion current density values with and without inhibitors, respectively.

From the Table 2, it is observed that the Ecorr values are shifted towards noble direction in the presence of optimum concentration of MBTA. This observation clearly shows that the MBTA control both cathodic and anodic reactions and thus acting as mixed type inhibitor.

Table 2. Electrochemical parameters and inhibition efficiency of brass in $3 \% \mathrm{NaCl}$ solution containing optimum concentration of MBTA

\begin{tabular}{lccc}
\hline $\begin{array}{c}\text { Inhibitor } \\
\text { concentration, ppm }\end{array}$ & $\begin{array}{c}\text { Icorr } \\
\mu \mathrm{Acm}^{-2}\end{array}$ & $\begin{array}{c}\text { Corrosion rate } \\
\text { mils year }^{-1}\end{array}$ & $\begin{array}{c}\text { Inhibition } \\
\text { Efficiency, } \%\end{array}$ \\
\hline Blank & 23.33 & 1.15 & - \\
MBTA $(150 \mathrm{ppm})$ & 7.42 & 0.70 & 68.17 \\
\hline
\end{tabular}

\section{AC impedance studies}

The corrosion behavior of brass in $\mathrm{NaCl}$ solution and with MBTA was investigated by electrochemical impedance spectroscopy at room temperature. Various impedance parameters such as charge transfer resistance (Rct), and IE are given in Table 3. The (Rct) were calculated from the difference in impedance at the lower and higher frequencies as suggested by Haruyama et al., ${ }^{25}$. Nyquist plots of brass in inhibited and uninhibited $\mathrm{NaCl}$ solution containing optimum concentrations of $150 \mathrm{ppm}$ MBTA are shown in Figure 3. The IE\% of corrosion of brass is calculated by the following equation: ${ }^{26}$,

$$
\mathrm{IE} \%=[\mathrm{Rct}]^{-1}-[\operatorname{Rct}(\mathrm{inh})]^{-1}[\mathrm{Rct}]^{-1} \times 100
$$

Table 3. Impedance measurements and inhibition efficiency of brass in $3 \% \mathrm{NaCl}$ containing optimum concentration of MBTA

\begin{tabular}{lcc}
\hline \multicolumn{1}{c}{ Inhibitor } & Rct & Inhibition \\
concentration, ppm & $\Omega$ & Efficiency, \% \\
\hline Blank & 4977 & - \\
MBTA $(150 \mathrm{ppm})$ & 13040 & 61.80 \\
\hline
\end{tabular}

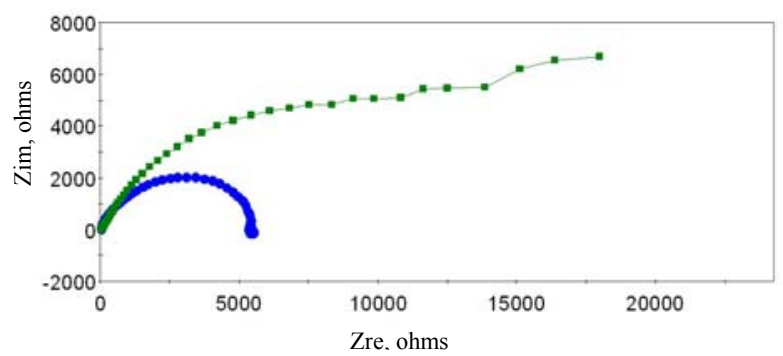

Figure 3. Nyquist diagram for brass in $3 \% \mathrm{NaCl}(\mathrm{O} \rightarrow$ blank, $\square \rightarrow 150$ pppm MBTA)

Where Rct(inh) and Rct are charge transfer resistance values with and without inhibitors, respectively. In the presence of inhibitor, Rct values increased. It suggests that the MBTA function by adsorption at the metal-solution interface. The change in Rct values was caused by the gradual replacement of water molecules by the anions of the $\mathrm{NaCl}$ and adsorption of the organic molecules on the metal surface, reducing the extent of dissolution. 


\section{Analysis of FTIR spectra}

The FTIR analysis of blank and MBTA- copper complex was carried out between 500 and $4000 \mathrm{~cm}^{-1}$. The spectra are shown in Figure 4 and 5. The N-H stretching of MBTA showed a sharp intense peak around $3400 \mathrm{~cm}^{-1}$. The aliphatic and aromatic $\mathrm{C}-\mathrm{H}$ stretching produced a less intense peak between 2900 and $3100 \mathrm{~cm}^{-1}$.

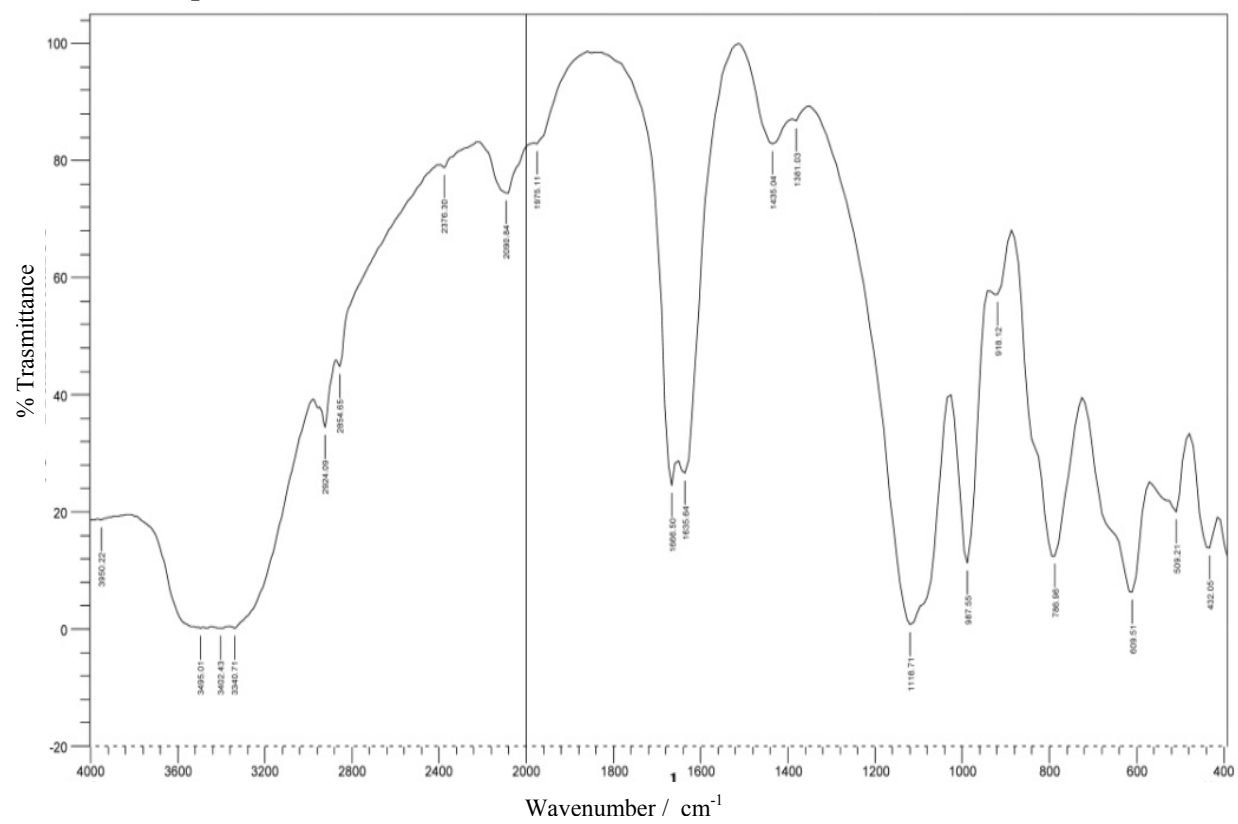

Figure 4. FTIR spectra (Blank)

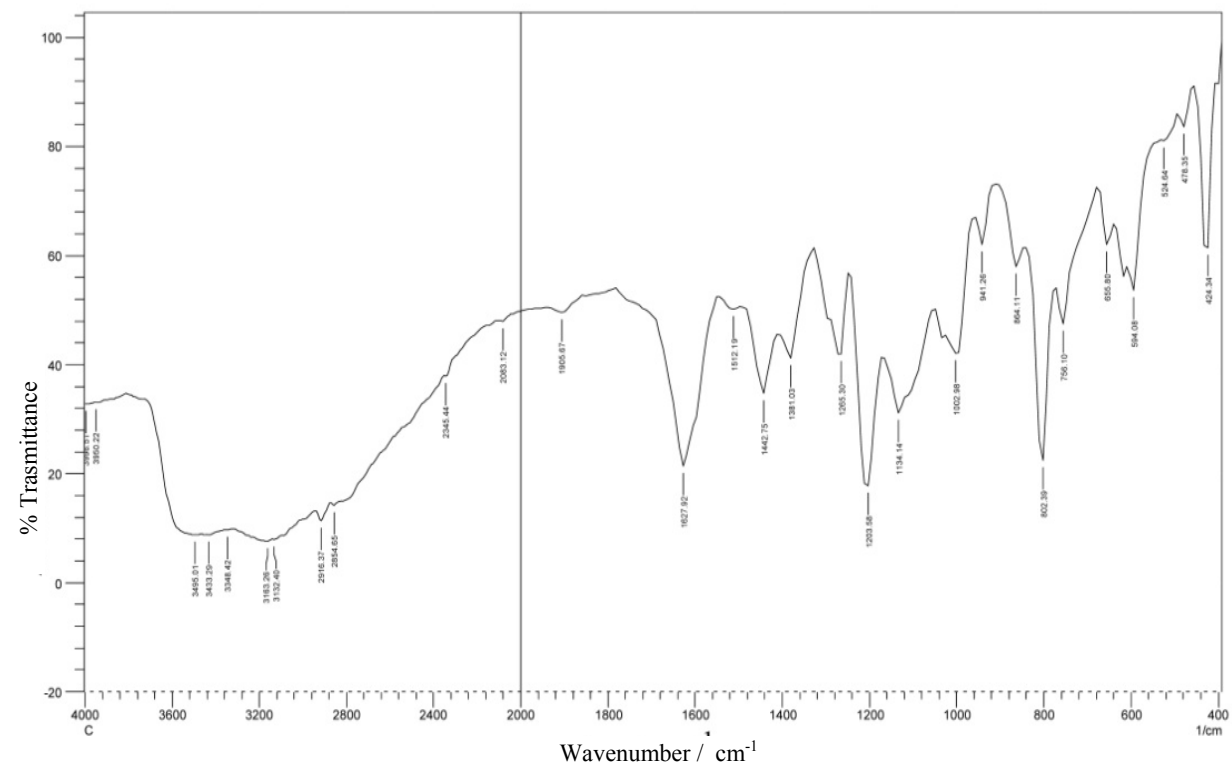

Figure 5. FTIR spectra (MBTA-copper complex) 
The N-H bends are shown around $1500-1600 \mathrm{~cm}^{-1}$ and the $\mathrm{C}-\mathrm{N}$ stretching vibrations are shown with an intense peak around $1300-1450 \mathrm{~cm}^{-1}$. The presence of MBTA over the oxide surface is well evidenced by the aromatic $\mathrm{C}-\mathrm{H}$ stretch lying just above $3000 \mathrm{~cm}^{-1}$. The peak around $1000 \mathrm{~cm}^{-1}$ in the MBTA-copper complex is due to $\mathrm{O}-\mathrm{Cu}-\mathrm{O}$ vibration. The spectral data confirmed the formation of $\mathrm{Cu}$-MBTA inhibitive complex on the metal surface.

\section{Conclusion}

- Weight loss data shows quantitatively the inhibitor exhibit $71 \%$ IE on Brass in $3 \% \mathrm{NaCl}$ solution.

- When the concentration of inhibitor increases IE also increases and reaches a maximum value at $150 \mathrm{ppm}$ concentration.

- The potentiostatic polarization studies indicate that both cathodic and anodic processes are controlled equally and the inhibitor behaves as a mixed type.

- $\quad$ EIS studies confirms the formation of metal-inhibitor complex on the corroding sites.

\section{Acknowledgement}

I thank sincerely the Management, the Principal and the Department of Chemistry for their valuable support and guidance in this endevour.

\section{References}

1. Joseph X and Rajendran N, Int J Electrochem Sci., 2011, 6, 348-366.

2. Gasparac R,.Martin C R and Stupnisek-Lisac E, J Electrochem Soc., 2000, 147, 548.

3. Zaky A M, Br Corros J., 2001, 36, 59.

4. Antonijevic M M, Milic S M, Radovanovic M B, Petrovic M M and Stamenkovic A T, Int J Electrochem Sci., 2009, 4, 1719-1734.

5. Ravichandran R and Rajenderan N, Appl Surface Sci., 2005, 241, 449.

6. Osman M M, Mater Chem Phy., 2001, 71, 12.

7. Quaraishi M A, Farooqi I H and Saini P A, Br Corros J., 2000, 35, 78.

8. $\quad$ Shih H C and Tzou R J, J Electrochem Soc., 1991, 138,958.

9. Quartarone G, Moretti G and Bellami T, Corros., 1998, 54, 606.

10. Lee W J, Mater Sci Eng., 2003, 348, 217.

11. Mamas S, Koc A, Kiyak T and Kabasakaloglu M, Mater Chem Phys., 2005, 93, 41.

12. Quartaranac G, Zingales A, Bellomi T, Bonaldo L, Gajo M and Paolucci G, Corros., 2005, 61,1041.

13. Ravichandran R, Nanundan S and Rajenderan N, Appl Surface Sci., 2004, 236, 241.

14. Ling Y, Guan Y and Ham K N, Corros., 1995, 51, 267.

15. Tromans J C and Silva, Corros., 1997, 53, 16.

16. Frignani A, Tommesani L, Brunoro G, Monticelli C and Fogagnolo M, Corros Sci., 1999, 41, 1205.

17. Cruz J, Garcia-Ochoa E and Castro M, J Electrochem Soc., 2003, 150, B26.

18. Scendo M and Malyszko J, J Appl Electrochem., 2000, 147, 1758.

19. Al-Kharafi F M and Ateya B G, J Electrochem. Soc., 2002, 149, 206.

20. Warraky A A E L, Br Corros J., 1997, 32, 57.

21. Petkova G, Sokolova E and Ivanov P, Br Corros J., 1996, 31, 55.

22. Gasparac R and Mandic Z, J Electrochem Soc., 2000, 147, 991.

23. Bag S K, Chakraborty B, Roy A and Chaudhuri S.R, Br Corros J., 1996, 31, 207.

24. Khamis E, El-Ashry E S H, Ibrahim A K, Br Corros J., 2000, 35, 150.

25. Xia Z and Szklarska-Smialowska Z, Corros., 1990, 46, 85.

26 Quraishi M A and Sardar R, J Appl Electrochem, 2003, 33, 1163-1168. 